\title{
Stroke Due to Hypercoagulable State Can Mimic Multiple Sclerosis: A Case Report
}

\section{Niknam Zahra', Saadat Alireza' ${ }^{2}$, Nabavi Seyed-Massood ${ }^{3}$, Morsali Damineh" Hatami-Sadabadi Farhad5, Kheirkhahan Meghdad5, Mehdipour Baharak ${ }^{5 *}$}

\author{
${ }^{1}$ Neurologist, Neurology Department, University of Baghiatalahaazam, Tehran, Iran \\ ${ }^{2}$ University of Baghiatalahaazam, Tehran, Iran \\ ${ }^{3}$ Department of Regenerative Biomedicine, Cell Science Research Center, Royan Institute for Stem Cell Biology and Technology, \\ ACECR, Tehran, Iran \\ ${ }^{4}$ Senior postdoctoral fellow, Neurology department, Texas University, Huston, Texas, USA \\ ${ }^{5}$ General physician, Kheradmand Clinical Research Center, Medical Affairs Division, Actoverco Pharmaceutical Company, \\ Tehran, Iran \\ Email: mehdipour55@gmail.com
}

How to cite this paper: Zahra, N., Alireza, S., Seyed-Massood, N., Damineh, M., Farhad, H.-S., Meghdad, K. and Baharak, M. (2017) Stroke Due to Hypercoagulable State Can Mimic Multiple Sclerosis: A Case Report. World Journal of Neuroscience, 7, 267-274.

https://doi.org/10.4236/wjns.2017.73022

Received: January 16, 2017

Accepted: July 3, 2017

Published: July 6, 2017

Copyright (c) 2017 by authors and Scientific Research Publishing Inc. This work is licensed under the Creative Commons Attribution International License (CC BY 4.0).

http://creativecommons.org/licenses/by/4.0/

\begin{abstract}
Introduction: Stroke is the second major cause of mortality worldwide and in several cases, and it may lead to disability. Factor $\mathrm{V}$ Leiden is a common genetic thrombophilia, which causes activated protein C (APC) resistance. Hyperhomocysteinemia and factor $\mathrm{V}$ Leiden deficiency, two independent coagulopathy factors, can lead to venous and arterial infarctions in multiple small and large arteries and veins anywhere in the body. Case Report: Here, we report a unique case in which both hyperhomocysteinemia and factor V Leiden deficiency are documented together with MTHFR (C677T) (Methylene Tetra Hydro Folate Reductase) gene polymorphism and activated protein $\mathrm{C}$ resistance respectively. Conclusion: More interestingly, the mode of presentation in this case highly resembled that of progressive multiple sclerosis; all signs and symptoms slowly progressed without any systemic signs at first few years. Further studies needed to assess current outcomes.
\end{abstract}

\section{Keywords}

Hyperhomocysteinemia, Thrombophilia V, MTHFR (C677T) Gene

Polymorphism, Activated Protein C Resistance, Multiple Sclerosis

\section{Introduction}

Homocysteine (Hcy) is a sulfur-containing amino acid, which produced during the metabolism of methionine.

Deficiency of vitamin B12 and or folate may cause increased plasma levels of 
Hcy. As well, genetic factors such as C667T can cause elevated Hcy (eHcy). Several medical conditions, such as multiple sclerosis, epilepsy, eclampsia, Parkinson's disease, dementia, cardiovascular disorders, atherosclerosis, myocardial infarction, stroke and minimal cognitive impairment may cause eHcy [1].

Factor V Leiden thrombophilia described by a poor anticoagulant responses to activated protein $\mathrm{C}$.

Hyperhomocysteinemia and factor V Leiden deficiency, two independent coagulopathy factors, can lead to venous and arterial infarctions in multiple small and large arteries and veins anywhere in the body.

\section{Case Presentation}

The patient was a 45-year-old woman who slowly developed progressive paresis in her right lower and left upper extremities within few weeks. She referred to a neurologist and had brain MRI (Magnetic Resonance Imaging) done. Based on her symptoms and the findings from her MRI, Multiple Sclerosis (MS) diagnosed for her. She received five doses of methylprednisolone $(1 \mathrm{~g} /$ day $)$ for 5 days and then beta interferon 1-a (Rebif) started but it was halted after 21 days due to non-compliance. She had no follow-up for 2 years, and then she returned due to worsening of presenting symptoms (paresis of right lower and left upper extremities). She advised having a course of hyperbaric oxygen therapy. South Africa neurology consultation (SA neurology consultation) had done within our department and we visited the patient for the first time. At this stage, the original diagnosis with MS was largely in doubt and therefore hyperbaric oxygen therapy did not seem to be a logical approach; she admitted to our ward for further examinations to confirm the diagnosis. In her first visit she was alert, awake and had normal Mental Status Examination; cranial nerves were normal, motor power of right lower and left upper extremities were 3/5, distal weaker than proximal. Right upper and left lower extremities were $4 / 5$. Deep tendon reflexes (DTR) were $2 / 2$, both plantar reflexes were flexor. There were no sensory deficit findings (fine touch, pinprick, position sense, and temperature). The patient could hardly walk with walking aid. Findings from routine laboratory examination (CBC, BUN, Cr., electrolytes, lipid profiles and FBS) were normal. Because of a history of abortion 10 years ago and unusual presentation of the neurologic problem, and because lesions in brain MRI were not typical for MS, we did an extended laboratory workup. In hematologic workup, factor V Leiden deficiency and Hyperhomocysteinemia were detected.

Following the MRI, results were mostly in favor of vascular origin of her brain lesions Warfarin treatment had started. The results of the rheumatologic, hematological w/u and blood chemistry results shown in the table (Table 1). She discharged after a course of physiotherapy with INR (International Normalized Ratio): 2.3 with the same but stable condition.

CSF (Cerebrospinal fluid) profile was normal with nooligoclonal bands. Brain SPECT (Single-Photon Emission Computed Tomography) study by TC $99 \mathrm{~m}$ EDC (Technetium 99 m-Ethyl Cysteine Dimer) impressed bilateral hypoperfu- 
Table 1. Findings laboratory examination.

\begin{tabular}{|c|c|c|c|}
\hline & Results & Units & References value \\
\hline Fibrinogen & 330.7 & $\mathrm{mg} / \mathrm{dl}$ & $150-400$ \\
\hline Homocysteine & 21.4 & umol/1 & Female $41-50$ y/o: 6.4 to 13.2 \\
\hline Lupus-like anticoagulants & 46 & $\mathrm{sec}$ & $18-55$ \\
\hline Protein C & $134-172$ & $\%$ & $70-135$ \\
\hline Protein S & 60 & $\%$ & $55-123$ \\
\hline APC-R (Factor V Leiden) & 72 & $\sec$ & $>120$ \\
\hline Antithrombin III & 110 & $\%$ & $80-120$ \\
\hline \multicolumn{4}{|l|}{ Rheumatologic w/ $u$} \\
\hline ESR & 20 & $\mathrm{~mm}$ & \\
\hline Complement C3 & 141 & $\mathrm{mg} / \mathrm{dl}$ & $90-180$ \\
\hline Complement $\mathrm{C} 4$ & 25 & $\mathrm{mg} / \mathrm{dl}$ & $10-40$ \\
\hline $\mathrm{CH} 50$ & 116 & $\%$ & $70-150$ \\
\hline Anti-ds-DNA(ELISA) & 0.4 & ISR & $<0.9$ : negative \\
\hline ANA & 3.5 & & $<1.0$ : negative \\
\hline ANCA $(C \& P)$ & Negative & & \\
\hline Anticardiolipin (IgG) & 4 & $\mathrm{GPL} / \mathrm{ml}$ & $<10$ : Negative \\
\hline Anticardiolipin (IgM) & 4 & $\mathrm{MPL} / \mathrm{ml}$ & $<7$ : Negative \\
\hline Antiphospholipid (IgG) & 4.7 & IU/ML & 0 - 8 Negative \\
\hline Antiphospholipid (IgM) & Negative & & \\
\hline C-reactive protein & Negative & $\mathrm{mg} / \mathrm{dl}$ & $<6$ Negative \\
\hline Rheumatoid Arthritis Factor & Negative & & \\
\hline \multicolumn{4}{|l|}{ Infections $w / u$} \\
\hline Serum HTLV 1 & Negative & & \\
\hline HBs/AG (ELA) & Negative & & \\
\hline Wright agglutination test & Negative & & \\
\hline Widal agglutination test & Negative & & \\
\hline VDRL & Negative & & \\
\hline PPD & Negative & & \\
\hline
\end{tabular}

sion of frontoparietal lobes especially on somatosensory cortices suggestive of atrophic changes.

After two years with no visits, she admitted because of deep vein thrombosis. She had discontinued warfarin due to non-compliance. After the proper treatment, she discharged on warfarin $5 \mathrm{mg}$ per day. INR adjusted on 2.5. Three weeks later she referred to our clinic again due to meno-metrorhagia (Hgb was 5.5, INR: 2.3). She admitted and received two bags of packed RBC (Red Blood cell Count). Warfarin discontinued and the bleeding stopped. In this last admission she was seriously depressed, very bedridden, motor power of extremities 
were all $1 / 5$, and atrophy of the distal parts was obvious. DTR was not detected and both plantar reflexes were extensor. Cranial nerves were normal. Fine touch and pinprick were normal but position and vibration senses were obviously abnormal.

Imaging

The first brain MRI obtained, at the beginning of the disease onset, was indicative of convalescent hyper signal lesions in both parietal lobes on T2WI (T2weighted spin echo pulse sequences) and were non-enhancing Cervical MRI was normal. Two years later, when we saw the patient for the first time, MRI imaging showed non-enhancing hyper signal lesions in cerebral white matter, corpus callosum, brain stem and cervical cord on T2WI. Some small lesions of centrum semi oval were necrotic. In the last MRI at the last admission, there was a defined focus of high signal intensity within cervical cord.

The preceding images (Figures 1-3) were taken in the last admission. No contrast enhancing was noted so the images, which were taken with Gad-enhancing, are not shown there.

Pathobiology

Patient's peripheral blood leukocyte (WBC) was collected for genomic DNA extraction followed by Real-Time PCR analysis using specific primers. The results were positive for factor V Leiden (G 1691A, heterozygote), and for MTHFR (MethylenTetraHydroFulateReductase) (C677T, homozygote), but negative for Prothrombin (G20210A), factor XIII; tested by PCR-RFLP (Restriction Frag-

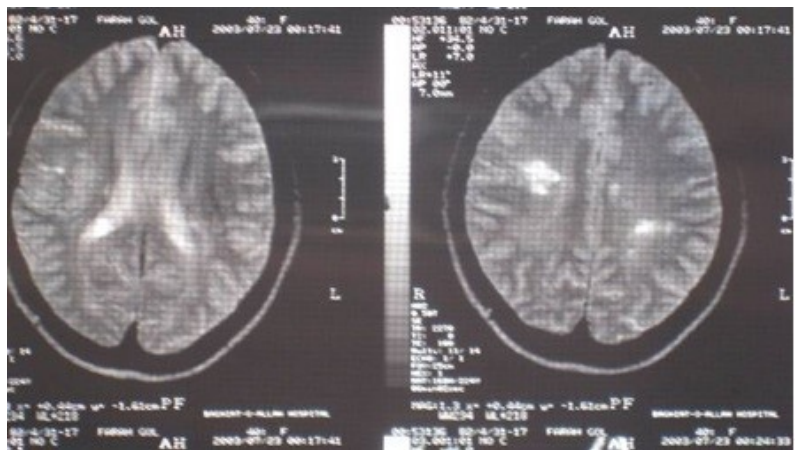

Figure 1. Bilateral white matter T2 hyperintense lesions in subcortical and priventricular area of brain in axial images.

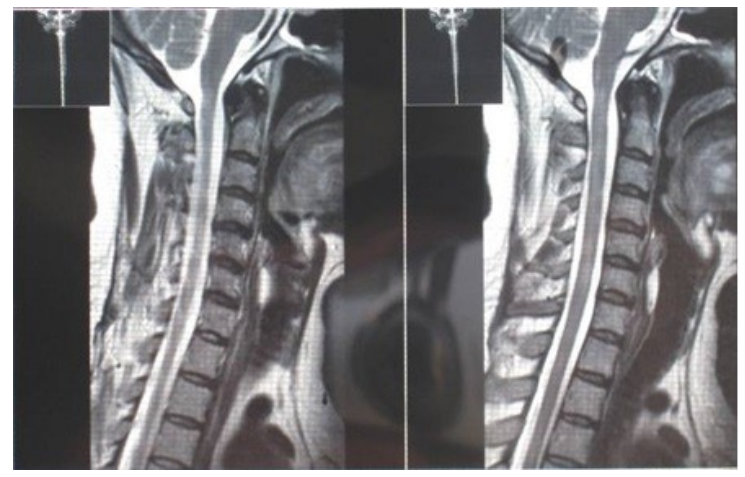

Figure 2. Patchy spinal cord involvement in sagital T2 image. 


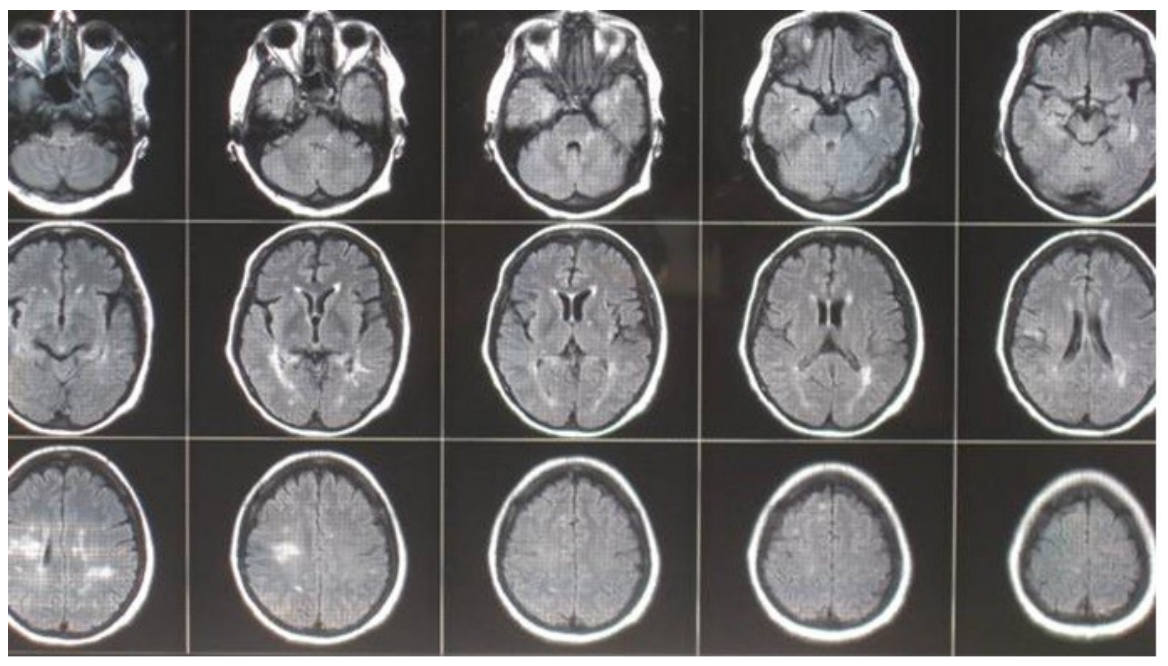

Figure 3. Multiple white matter T2 hyper intense lesions in supra and infra tentorial regions in axial T2 FLAIR brain images.

ment Length Polymorphism) method and Plasminogen activator inhibitor (PAI)-1 disease which was checked by ARMs-PCR method.

\section{Discussion}

Epidemiological evidence indicates that moderately elevated plasma homocysteine levels constitute an important risk factor for ischemic stroke [2] [3].

Various studies have shown a strong association between hyperhomocysteinemia and the homozygous C677T mutation in the MTHFR gene [4] [5].

Moreover, Elkelboom and colleagues have reported that hyperhomocysteinemia was associated with large artery atherosclerosis [6]. Furthermore, no association was found between the 677TT genotype and the stroke subtypes [7] [8]. However, there is a strong association between Hyperhomocysteinemia and the C677TT genotype in multiple small artery occlusions [9].

In 1994, Bettina and colleagues described a common variation (G 1691A) in the factor $\mathrm{V}$ gene as a molecular defect responsible for activated protein C (APC) resistance, a previously unrecognized mechanism of inherited thrombophilia [10] [11]. The three common gene anomalies associated with venous thromboembolism (factor V Leiden mutations, prothrombin G20210A mutation and MTHFR C677T mutation) increased the risk of arterial thrombotic events to modest degree especially in patients younger than 55 years [11] [12] [13].

The case of our patient reported here is unique because:

1- Three systems are involved simultaneously: molecular defect in factor $\mathrm{V}$ Leiden (G 1691Avariant), MTHFR C677T mutation and Hyperhomocysteinemia.

2- The presentation is purely neurologic in the first few years until deep vein thrombosis occurred after discontinuing warfarin. MTHFR, Hyperhomocysteinemia, and factor $\mathrm{V}$ Leiden deficiency lead to multiple infarctions in both the brain and spinal cord. The progressive step, identified by the worsening of her neurological signs and symptoms, lead to the incorrect diagnosis of Multiple 
Sclerosis at first, but the case presented here emphasizes the importance of ruling out any other possible explanations that resemble signs and symptoms of MS prior to making the definite diagnosis of MS and starting the treatment.

\section{Conclusion}

More interestingly, the mode of presentation in this case highly resembled that of progressive multiple sclerosis; all signs and symptoms slowly progressed without any systemic signs at first few years. Further studies needed to assess current outcomes.

\section{Acknowledgements}

Special thanks to Actoverco Pharmaceutical Company.

\section{Competing Interests}

The authors declare that they have no competing interests.

\section{References}

[1] Ansari, R., Mahta, A., Mallack, E. and Luo, J. (2014) Hyperhomocysteinemia and Neurologic Disorders: A Review. Journal of Clinical Neurology, 10, 281-288. https://doi.org/10.3988/jcn.2014.10.4.281

[2] Alfthan, G., Pekkanen, J., Jauhiainen, M., et al. (1994) Relation of Serum Homocysteine and Lipoprotein Concentration to Atherosclerotic Disease in a Prospective Finnish Population Based Study. Atherosclerosis, 106, 9-19. https://doi.org/10.1016/0021-9150(94)90078-7

[3] Satheesan, S.K., Sreedharan, S.T. and Warrier, P.K. (2017) Serum Homocysteine as a Risk Factor in Ischaemic Stroke-A Cross-Sectional Observational Study in a Tertiary Care Teaching Hospital in Northern Kerala. Journal of Evidence Based Medicine and Healthcare, 4, 163-167.

[4] Boushey, C.J., Beresford, S.A., Omenn, G.S. and Motulsky, A.G. (1995) A Quantitative Assessment of Plasma Homocysteine as a Risk Factor for Vascular Disease; Probable Benefits of Increasing Folic Acid Intakes. JAMA, 274, 1049-1057. https://doi.org/10.1001/jama.1995.03530130055028

[5] Coull, B.M., Malinow, M.R., Beanner, N., Sexton, G., Nordt, F., et al. (1990) Elevated Plasma Homocysteine Concentration as a Possible Independent Risk Factor for Stroke. Stroke, 21, 572-576. https://doi.org/10.1161/01.STR.21.4.572

[6] Eikelboom, J.W., Hankey, G.J., Anand, S.S., Lofthouse, E., Staples, N., et al. (2000) Association between High Homocysteine and Ischemic Stroke Due to Large and Small Artery Disease but No Other Etiologic Subtypes of Ischemic Stroke. Stroke, 31, 1069-1075. https://doi.org/10.1161/01.STR.31.5.1069

[7] Markus, H.S., Ali, N., Swaminathen, R., Sankaralingam, A., Molloy, J., et al. (1997) A Common Polymorphism in the Methylenetetrahydrofolate Reductase Gene, Homocysteine, and Ischemic Cerebrovascular Disease. Stroke, 28, 1739-1743. https://doi.org/10.1161/01.STR.28.9.1739

[8] Szolnoki, Z., Somogyvari, F., Szabó, M. and Fodor, L. (2002) Evaluation of the Interactions of Common Genetic Mutations in Stroke Subtypes. Journal of Neurology, 249, 1391-1397. https://doi.org/10.1007/s00415-002-0848-4

[9] Choi, B.O., Kim, N.K., Kim, S.H., Kang, M.S., Lee, S., et al. (2003) Homozygous 
C677T Mutation in the MTHFR Gene as an Independent Risk Factor for Multiple Small-Artery Occlusions. Thrombosis Research, 111, 39-44.

https://doi.org/10.1016/j.thromres.2003.08.022

[10] Bertina, R.M., Koeleman, B.P.C., Koster, T., Rosendaal, F.R., Dirven, R.J., et al. (1994) Mutation in Blood Coagulation Factor V Associated with Resistance to Activated Protein C. Nature, 369, 64-67. https://doi.org/10.1038/369064a0

[11] Dahlback, B., Carlson, M. and Svensson, P.J. (1993) Familial Thrombophilia Due to a Previously Unrecognized Mechanism Characterized by Poor Anticoagulant Response to Activated Protein C. Proceedings of the National Academy of Sciences of USA, 90, 1004-1008. https://doi.org/10.1073/pnas.90.3.1004

[12] Kim, R.J. and Becker, R.C. (2003) Association between Factor V Leiden, Prothrombin G20210A, and Methylenetetrahydrofolate Reductase C677T Mutations and Events of the Arterial Circulatory System: A Meta-Analysis of Published Studies. American Heart Journal, 146, 948-957. https://doi.org/10.1016/S0002-8703(03)00519-2

[13] Silver, R.M., Saade, G.R., Thorsten, V., et al. (2016) Factor V Leiden, Prothrombin G20210a, and Methylene Tetrahydrofolate Reductase Mutations and Stillbirth: The Stillbirth Collaborative Research Network. American Journal of Obstetrics Gynecology, 215, 468.e1-468.e17. https://doi.org/10.1016/j.ajog.2016.04.026 


\section{Abbreviations}

MTHFR: Methylene Tetra Hydro Folate Reductase;

APC: Activated Protein C;

Hcy: Homocysteine;

eHcy: elevated Homocysteine;

MRI: Magnetic Resonance Imaging;

SA Neurology Consultant: Neurology Consultation in South Africa;

MS: Multiple Sclerosis;

CBC: Complete Blood Count;

BUN: Blood Urea Nitrogen;

Cr.: Creatinine;

FBS: Fasting Blood Sugar;

INR: International Normalized Ratio;

CSF: Cerebrospinal Fluid;

SPECT: Single-Photon Emission Computed Tomography;

TC 99m-EDC: Technetium 99m-Ethyl Cysteine Dimer;

Hgb: Hemoglobin;

RBC: Red Blood Cell Count;

DTR: Deep Tendon Reflex;

T2WI: T2-Weighted Spin Echo Pulse Sequences;

WBC: White Blood Cell Count;

DNA: Deoxyribonucleic Acid;

PCR: Polymerase Chain Reaction;

RFLP: Restriction Fragment Length Polymorphism;

PAI: Plasminogen Activator Inhibitor;

ARMs: Amplification-Refractory Mutation System.

Submit or recommend next manuscript to SCIRP and we will provide best service for you:

Accepting pre-submission inquiries through Email, Facebook, LinkedIn, Twitter, etc. A wide selection of journals (inclusive of 9 subjects, more than 200 journals) Providing 24-hour high-quality service User-friendly online submission system Fair and swift peer-review system Efficient typesetting and proofreading procedure Display of the result of downloads and visits, as well as the number of cited articles Maximum dissemination of your research work

Submit your manuscript at: http://papersubmission.scirp.org/

Or contactwjns@scirp.org 